\title{
Kadınlarda Laparoskopik Artifisyel Üriner Sfinkter Uygulamaları
}

\author{
Cenk Gürbüz ${ }^{1}$, Rasim Güzel ${ }^{1}$
}

${ }^{1}$ Medistate Kavacık Hastanesi, Üroloji Kliniği, İstanbul

\section{Giriş}

A rtifisyel üriner sfinkter (AÜS) erkek cinsiyette üriner sfinkterik direncin kaybolması sonucu oluşan özellikle orta-şiddetli üriner inkontinans (Üi) tedavisinde uzun dönem etkinlik ve güvenilirliği ispatlanmış bir yöntemdir $(1,2)$. Dünya genelinde en sık uygulanan AÜS tipi AMS 800 (AMS, Minnetonka, MN, USA) modelidir (3). Erkeklerde uygulanma nedeni postprostatektomik inkontinans olarak sıklıkla rapor edilmiştir (4). Kadında AÜS endikasyonları; tek başına ya da üretral hipermobilite ile birlikte var olan şiddetli Üİ, nüks Üİ ya da diğer tedavi yöntemleri ile düzeltilemeyen sfinkter yetmezliğine bağlı stres inkontinanstır (5) .

Kadınlarda görülen Stres tip idrar kaçırma (STIK) tedavisinde transobturator tape gibi sentetik orta üretra askı cerrahileri, sentetik olmayan mesane boynu askı cerrahisi, açık ya da laparoskopik kolposüspansiyon daha yaygın olarak tercih edilmektedir. Erkek hastalarda kendisine önemli bir yer bulan ve sık bir şekilde uygulanan AÜS yerleştirilmesi, kadınlardaki farklı kontinans mekanizmaları nedeniyle oldukça nadir uygulanan bir yöntemdir. Lee ve ark. ABD de yaptığı ankette kadınların ancak \%1'inde AÜS yerleştirildiği gösterilmiştir (6). Ülkemizde ise bu konuda uygulama oldukça azdır.

Bu çalışmada laparoskopik yardımlı AÜS yerleştirilmesinin endikasyonları, yöntemin kontinans başarısı, revizyon oranları, sfinkterin çıkarılma oranları, sfinkterin ortalama ömrü literatür eşliğinde değerlendirilmiştir.

\section{Artifisyel Üriner Sfinkter Yerleştirilmesinin Endikasyonları ve Hasta Seçimi}

İntrinsik sfinkter yetmezliği (ISY) ve normal mesane kompliyansina sahip yeterli mesane kapasitesi $(>200 \mathrm{~mL})$ olan hastalar AÜS uygulaması için uygun adaylardır. İSY için ürodinamik tanımlar geliştirilmiştir (7). En yüksek üretral kapanma basıncı $<30 \mathrm{~cm} \mathrm{H} 2 \mathrm{O}$ olması ISY için tek başına olmasa da yeterli bir bulgudur. Ürodinami dişında; klinik testler, dikkatli bir ürojinekolojik fizik muayene, sistoskopi, ped testi ve hayat kalitesi formları İK'ya yol açan mekanizmaların belirlenmesi ve hastaların değerlendirilmesinde önemlidir.

Detrusor aşırı aktivitesi olan hastalar üst üriner sistemin korunması, kaçırmanın azalması ve depolama şikayetleri açısından AÜS öncesinde antikolinerjik ajanlarla ya da uygun yöntemlerle tedavi edilmelidir. Üst üriner sistemi risk altına sokan düşük kompliyanslı ya da düşük basınç- larda reflüye yol açan kontrol edilmemiş mesane bulguları varlığında uygulanmamalı ya da bu patolojiler düzeltildikten sonra uygulanmalıdır.

\section{Kontrendikasyonlar}

AÜS, kognitif disfonksiyonda, bozulmuş üretral doku bütünlüğünde ve azalmış mesane kompliyansında kullanılmamalıdır. Radyoterapi sonrası erozyon oranı özellikle kadınlarda çok yüksek olduğu için AÜS bu grup hastalarda da uygulanmamalıdır (8).

\section{Uygulama öncesi Hazırlık}

Hastalar sfinkter uygulaması öncesi mutlaka detaylı olarak bilgilendirilmelidir. Yapılacak işlem, yapay sfinkter ve komponentleri, kullanım şekli, aktivasyon süresi, olası intraoperatif ve postoperatif komplikasyonlar, cihaz arızaları, erozyon, enfeksiyon ve diğer tüm detaylar hasta ile detaylı olarak tartışılmalıdır.

\section{Cerrahi Teknik}

Laparoskopik sling üretropeksi, intrensek sfinkter yetmezliği cerrahi tedavisinde ilk olarak Kreder ve Winfield tarafından rapor edildi (9). Cerrahi olarak mümkün olan bu işlemde mesane boynu ve proksimal üretranın anterior vajen duvarından diseksiyonu aşamasını en zor aşama olduğu belirtildi.

Schuessler ve Tecuanhuey'in laparoskopik sling işlemindeki ilk deneyimlerinde, üretral yaralanmanın elimine edilmesi, proksimal üretra etrafında $6-10 \mathrm{~mm}$ genişliğinde bir alan bırakılarak geniş bir diseksiyon yapılması önerildi (10).

Dorsal litotomi pozisyonda 20 Fr foley kateter mesaneye yerleştirilir. Umblikus üst veya altından $10 \mathrm{~mm}$ trokar açık ya da uygun güvenlik manevraları yapılarak insuflasyon ardına yerleştirilir. Trandelenburg pozisyona alındıktan sonra sigmoid ve ince bağırsaklar mobilize olur. Sağ ve sol iliak fossa 1 adet $10 \mathrm{~mm}$ ve ardından umblikus ile pubis arasındaki mesafenin ortasına 4 . Trokar yerleştirilir.

İlk basamak olarak parietal perion medial umblikal ligamanlar arasından açlarak mesane anterioruna ulaşılır. Mesane anterior ve lateral kısımdan serbestleştirilir ardından mesane boynu ve üretra ortaya konur.

Mesane balon kateter lokalizasyonunda mesane boynu tanımlanır ve her iki yanından $2 \mathrm{~cm}$ mesafe olacak şekilde 


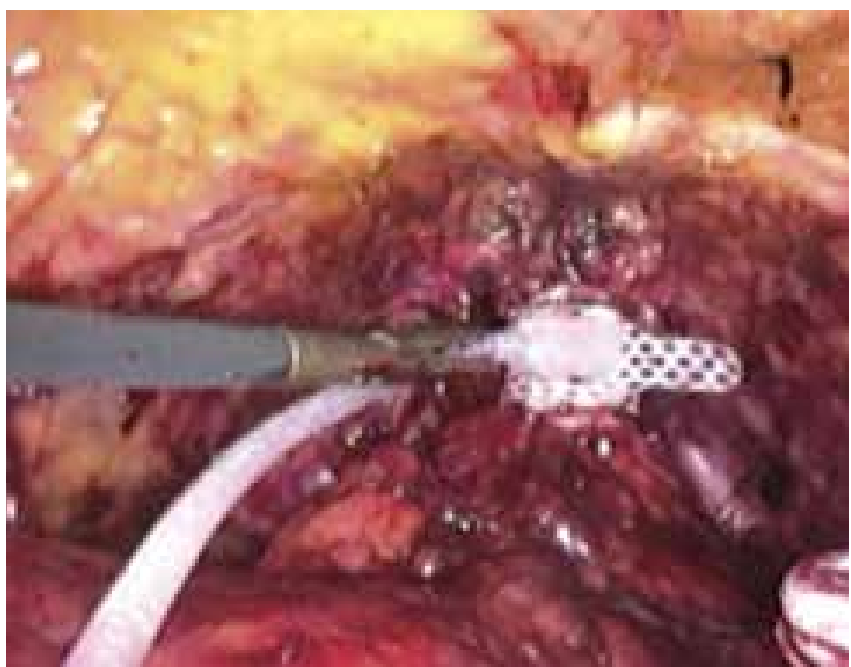

Şekil 1: Cuff ölçüm ve yerleştime

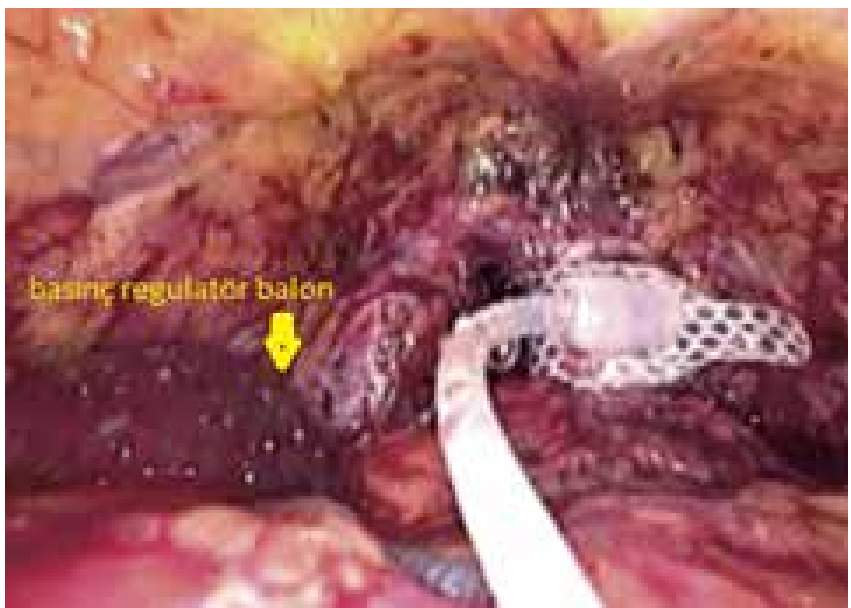

Şekil 2: Balonun yerleştirilmesi

Costa ve arkadaşlarının tarif ettiği metotla endopelvik fasya açılır (11). Cerrah bu aşamada vajenden sol el 2 parmağını ilerletir ve parmak yardımıyla tanımlanan alanda periuretral fasya boyunca diseksiyona, vajen tamamen görünür hale gelinceye kadar devam eder. Periuretral fasya altında vajinadan her iki yönde de kateter balonu seviyesinde mesabe boynu diseke edilir. Masane ya da vajen bütünlük bozulması varlığı kontrolü yapılır.

Mevcut sondanın 12 FR sonda ile değişimi yapıldıktan sonra üretral ölçüm teyp kullanılarak uygun cuff çapı belirlenir. Ardından cuff belirlenen alana yerleştirilir (Şekil 1). Basınç regülatör balon 4. porttan trokar çıkarıldıktan sonra insizyondan mesane boynu lateralindeki alana gönderilir (Şekil 2). Labium majustan yapılan insizyon ardına pompa yerleştirilir. Sağ iliak fossadan yapılan insizyonla ya da median port insizyonundan kablolar dışarı alınır (Şekil 3). Gerekli olan 25-35 cm su basıncı sağlamak için basınç ayarlayan balon genellikle 22 ya da $23 \mathrm{~mL}$ sivı ile doldurulur.

Daha sonra kaf, rezervuar ve kontrol pompasina ait tüp borular bağlanır. Bağlamadan önce ve işlemin her safhasında tüp borular özel enjektör ile sürekli sıvı verilerek "flush" yapılmalıdır. Tüp bağlantıları özel sıkıştıııcı ile yapıldıktan sonra sistem çalıştırılıp içindeki sıvının hareket etmesi ve kafı doldurup doldurmadığı kontrol edilir (Şekil 4).

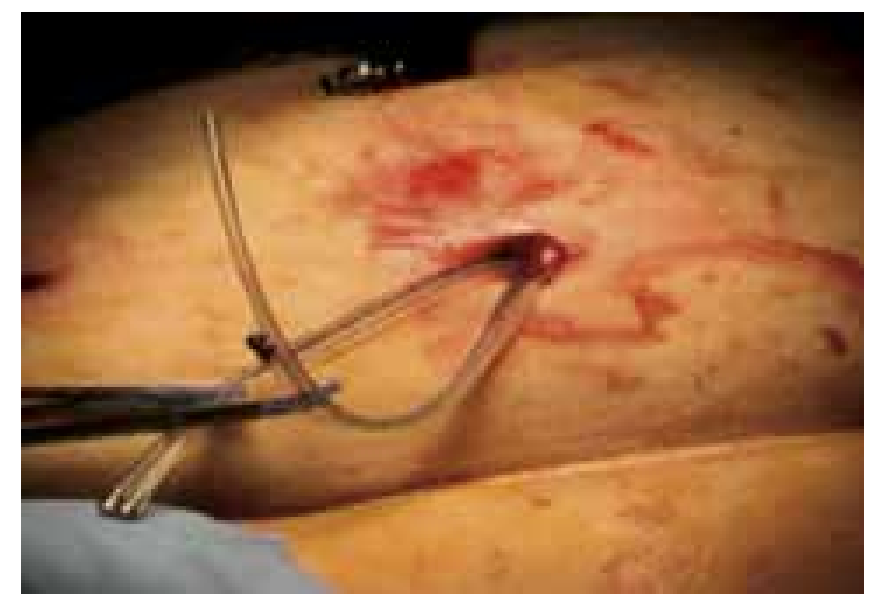

Şekil 3: Bağlantı kablolarının dışarı alımı

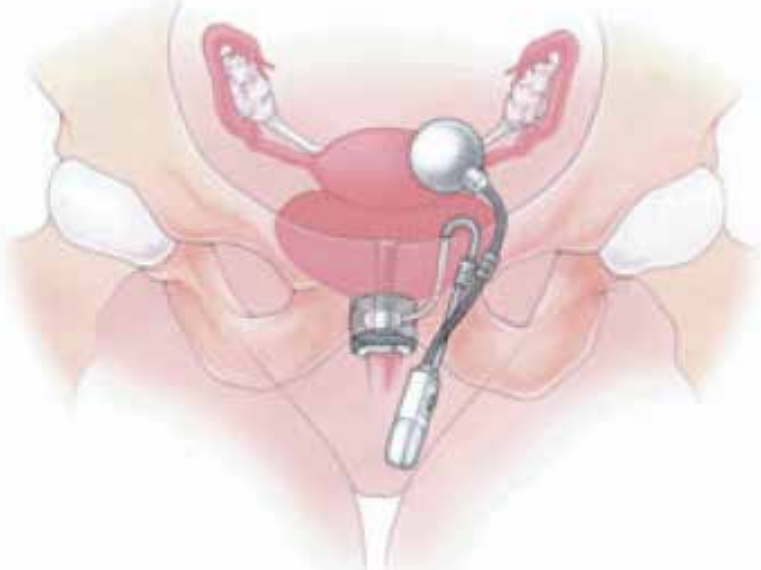

Şekil 4: AUS uygulama şematizasyon

\section{Artifisyel Üriner Sfinkter Yerleştirilmesi Sonuçları}

Literatürde; hasta sayısı sınırlı ve ortalama takip süreleri kısa olan olgu serileri yayınlanmıştır (Tablo 1). Çalışmaların tamamında kontinans, ıslatılan ped sayısı ile değerlendirilmiş olup hiçbir çalışmada İK değerlendirme formları kullanılmamıştır. AÜS yerleştirilmesi sonrası hastaların kontinans oranları \%75 ile \%100 arasında değişkenlik göstermektedir.

Laparoskopik yardımlı AUS uygulamasında en geniş ve en uzun takipli seride artan tecrübeyle beraber operasyon süresi 92 dakikaya düşürülmüştür. İyilik hali de açık teknik sonuçlarına yakınlaşmıştır (12).

\section{Sonuç}

Kadınlarda AÜS yerleştirilmesi endikasyonları sınırlı olup; özellikle başarısız İK cerrahisi/cerrahileri geçiren hastalarda son tedavi yöntemi olarak ve ağır İK olup etiyolojisinde İSY'nin ön planda olduğu durumlarda uygulanmaktadır. Uygun hasta grubunda uygulandığında AÜS yerleştirilmesinin kontinans sonuçlarının yüksek olduğu bildirilmiştir. Bu hastaların daha önceden geçirmiş oldukları cerrahiler, başarısız anti inkontinans cerrahileri uygun alan oluşturma aşaması için en önemli teknik zorluklardır. Bununla beraber 
eş zamanlı prolaps onarımlarına (promontorium fiksasayon) imkan verebilmektedir.

Protez ürünleri takılmadan önce bu konuda hasta beklentisi ve kullanım süresi içerisinde oluşabilecek revizyonlar konusunda hasta bilgilendirilmeli ve cerrahi ekip bu konuda hazırlıklı olmalıdır.

\section{Kısaltmalar}

İdrar kaçırma (İK)

Artifisyel üriner sfinkter (AÜS)

İntrinsik sfinkter yetmezliğinin (İSY)

\section{Kaynaklar}

1. Wessells H, Peterson AC. Surgical procedures for sphincteric incontinence in the male: The artificial genitourinary sphincter and perineal sling procedures. Campbell-Walsh Urology. 10th edition. Saunders 2290305, 2012

2. Montague DK, Angermeier KW. Postprostatectomy urinary incontinence: The case for artificial urinary sphincter implantation. Urology 55: 2-4, 2000

3. James MH1, McCammon KA. Artificial urinary sphincter for post-prostatectomy incontinence: a review. Int J Urol 21: 536-43, 2014

4. Staskin DR, Comiter CV. Surgical treatment of male sphincteric urinaryincontinence. The male perineal sling and artificial urinary sphincter. In: Campbell MF, Kavoussi LR, Novick AC, et al, editors. Campbell-Walsh urology. Philadelphia: WB Saunders;. 2391-404, 2006.

5. Roupret M, Chartier-Kastler E, Richard F. Artificial urinary sphincters in women: indications, techniques, results. Prog Urol 15:489-93, 2005;

6. Lee R, Te AE, Kaplan SA, Sandhu JS. Temporal trends in adoption of and indications for the artificial urinary sphincter. J Urol181:2622-7., 2009

7. Appell RA. Techniques and results in the implantation of the artificial urinary sphincter in women with type III stress urinary incontinence by a vaginal approach. Neurourol Urodyn 7:613-9, 1988
Outcome of the artificial urinary sphincter in female patients.

8. Thomas K, Venn SN, Mundy AR Outcome of the artificial urinary sphincter in female patients. J Urol. 167(4):1720-2, 2002

9. Kreder KJ, Winfield HN. Laparoscopic urethral sling for treatment of intrinsic sphincter dysfunction. J Endourol 10:255-7, 1996

10. Schuessler WW, Tecuanhuey LV. Laparoscopic pubovaginal sling procedure. J Urol;157:211., 1997

11. Costa P, Mottet N, Rabut B, Thuret R, Naoum KB,Wagner $\mathrm{L}$. The use of an artificial urinary sphincter in women with type III incontinence and a negative Marshall test. J Urol 165:1172, 2001

12. Ferreira C, Brychaert PE, Menard J, Mandron E Laparoscopic implantation of artificial urinary sphincter in women with intrinsic sphincter deficiency: Mid-term outcomes. Int J Urol. 24(4):308-313, 2017

13. Ngninkeu BN, van Heugen G, diGregorio M, Debie B, Evans A.Laparoscopic artificial urinary sphincter in women for type III incontinence:preliminary results. Eur Urol 47:793-7, 2005

14. Rouprêt M, Misraï V, Vaessen C et al. Laparoscopic approach for artificial urinary sphincter implantation in women with intrinsic sphincter deficiency incontinence: a single-centre preliminary experience. Eur Urol 57: 499-504, 2009

15. Ferreira C, Brychaert PE, Menard J, Mandron E.Laparoscopic implantation of artificial urinary sphincter in women with intrinsic sphincter deficiency: Mid-term outcomes. Int J Urol. 24(4):308-313, 2017

16. Hoda MR, Gauruder-Burmester A,Kümmel C, Nitzke T, Popken G.Management of female stress urinaryincontinence. Endoscopic extraperitonealartificial urinary sphincter - earlyexperience.Urologe A 47: 10048,2008

Yazışma Adresi:

Cenk Gürbüz,

Medistate Kavacık Hastanesi, Üroloji Kliniğii, İstanbul

Tel: +90 5323173186

e-mail: gurbuzcenk@yahoo.com 